Volumen 36, $\mathrm{N}^{\circ}$ 1, 2004. Páginas 5-17

Chungara, Revista de Antropología Chilena

\title{
HOMENAJE A DON LUIS ÁLVAREZ MIRANDA
}

Testimonios de Lautaro Núñez, Oscar Espoueys, Mario Orellana, Luis Briones, Mario Rivera, Erie Vásquez, Eliana Belmonte, Patricia Arévalo,

\section{Viviana Briones y Calogero Santoro}

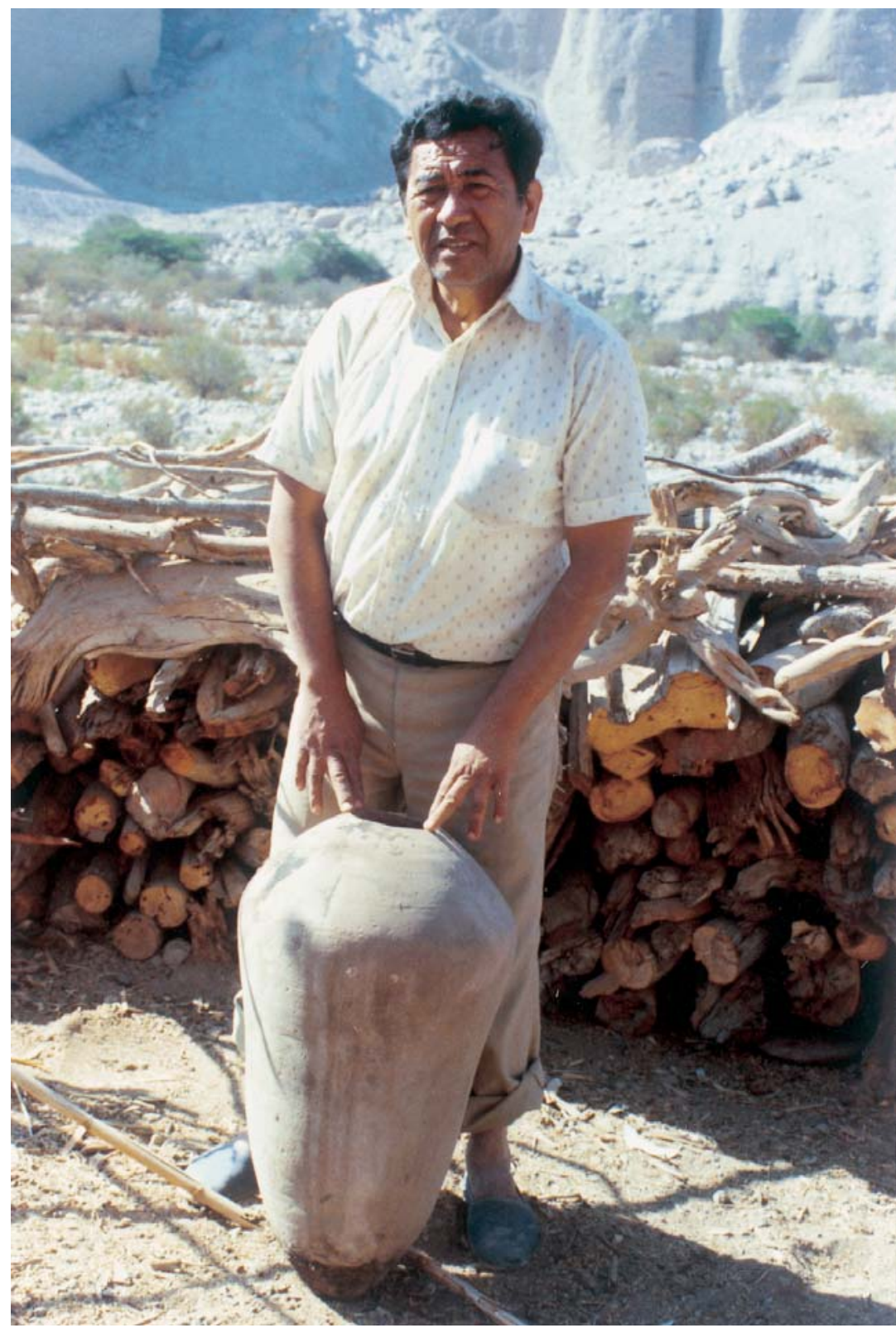

Luis Álvarez en Ausipar, valle de Azapa, 1982, en viaje de estudio con alumnas y alumnos de la carrera de pedagogía en Historia y Geografía (Fotografía gentileza de Patricia Arévalo). 


\section{Memorial del profesor Luis Álvarez Miranda, Lautaro Núñez A.*}

El profesor Luis Álvarez M. vive en la playa Chinchorro esquina caleta La Lisera y por ahora no atiende a sus familiares, amigos ni estudiantes, puesto que está dedicado jornada completa a bucear en su propia alma... Por cierto, no ha fallecido este hijo predilecto de las playas ariqueñas y, como las arenas trituradas por el oleaje, estará siempre allí, en ese vaivén perpetuo que nos recuerda que su vida construida con clase, esfuerzo y sentido sigue palpitando arrinconada en nuestras memorias, muy oculta, más allá del olvido y más cerca de aquellos otros hijos de esta tierra, Percy Dauelsberg y Guillermo Focacci, con quienes por el año 1960 observábamos una tumba en el gentilar de playa Miller.

El joven profesor por el año 1961 en esa Arica soñolienta, como en los tiempos de Uhle, se notaba preocupado por los primeros pescadores prehistóricos del litoral con las colecciones Chinchorro sobre un viejo tablero del museo de la calle Sotomayor. Así lo recuerdo junto a los escasos libros de arqueología de ese entonces, entre sus juicios tan asertivos sobre el uso de tantos implementos muertos, que en sus manos de chango antiguo cobraban un efecto de resurrección total. Sin duda, todo su ser extraviado en los enigmas de los tiempos debió radicarse en aquellos parajes costeros cuando Arica no lo era y la vida dependía de ese fascinante temblor de los anzuelos entre las cabrillas más voraces. Sí, es cierto, jamás volveré a conocer a un humano capaz de identificar a cada pájaro marino por su lenguaje y sus cobijos, a cada pez por su rostro y su estatura, aunque con mariscos sus recetas y beneficios eran parte del imaginario de Arica. Es que hay en él ese don antiguo de establecer un diálogo afectuoso y sabio con la naturaleza y sus misterios, como si su propia enarboladura mestiza, de esas de mástiles altos, siempre atrás, de su mirada penetrante y aceitunada, lo hiciera más pariente de los lobos de mar que de la más incierta y frágil biología humana, capacitado así para sus más íntimas navegaciones entre los otros seres.

Estudioso hasta la maestría, podía relacionar el conocimiento académico con el otro heredado de sus ancestros indios que le permitía oler más que aprender donde un valle era dulce y donde salado, cuando ascendía al interior del litoral tras su particular ecología subjetiva que amerita uno de los ensayos más magníficos e inconclusos. Cuánto de chango y de aymara había en él, mezclado para dar alma suelta a sus investigaciones y enseñanzas donde su historia y geografía, como sujeto y objeto del discurso, se le venía a flor de piel como si todos los muertos precoloniales y coloniales le susurraran los viejos sucesos de su propia tierra. Y, claro, con esas historias a cuestas transitaba por las calles saludo tras saludo, acompañado de esa leve sonrisa estirada lo suficiente para exponer la blancura de los más auténticos devoradores de cojinovas frescas. En verdad, sólo él podía olfatear desde Arica cuando el luche recalentado por el sol anunciaba una de las bajas más esperadas por los mariscadores de las orillas, para a continuación avanzar en sus tesis de Magíster entre fichas y estadísticas estivales.

En el Encuentro Arqueológico Internacional de Arica, patrocinado por la Universidad de Chile en su ex sede ariqueña, durante el año 1961, no sólo fue un gran protagonista el Museo Regional de Arica y sus publicaciones artesanales azules reproducidas a través de una increíble gelatina, sino la comprobación de tal fervor de convocatoria, que Percy, Guillermo, Sergio y Luis lograron reunir a los escasos estudiosos de Chile, Perú y Bolivia. En lo que hoy sabemos, fue el primer evento arqueológico, dando origen a la notable tradición chilena de reunirnos periódicamente para exponer nuestras contribuciones. Desde aquí surgió el acuerdo para fijar la próxima reunión en San Pedro de Atacama con Gustavo Le Paige a la cabeza y en una de esas sobremesas muy nocturna hasta se habló sobre la creación de una sociedad científica... entre tan pocos, que no sumábamos más de tres mesas de un hotel discreto. Allí Lucho lucía su tenida de profesor, sentado como una "L" rígida y perfecta, puesto que desde muy joven practicaba el buen andar, recto y armonioso hasta la elegancia, como el paso de aquellos antiguos rectores de liceo. Allí, sentado a mi lado escuchaba con atención a don Carlos Munizaga en su discurso por los invitados: “...Son ustedes personas dignas de la mayor alabanza y los pioneros de la arqueología en Arica, que, con una falta total de medios, no han escatimado esfuerzos en divulgar la ciencia que ha sido elogiosamente comentada... Arica se enorgullece de estos hombres"... Se produjo un largo silencio por esta notable

* Instituto de Investigaciones Arqueológicas y Museo, Universidad Católica del Norte, San Pedro de Atacama. 
legitimidad académica, justo para que el "Negro" me guiñara el ojo con la visión lateral de aquellos que dominamos el arte de la mirada de albacora. Estaba feliz, con esa criolla satisfacción sólo comparable al momento en que aquel chungungo mitológico hechizaba a las lobas cuando los machos salían de caza...

¿Cómo pesar su obra si en cada conversación había un trozo de su propia historia que se mediatizaba entre la academia y la naturaleza ariqueña desde los Andes al Pacífico? Por cierto, el profesor Álvarez no ha fallecido... sólo se trasladó a la playa Chinchorro esquina caleta La Lisera... Por ahora no atiende a sus familiares, amigos, ni estudiantes... está dedicado jornada completa a bucear en su propia alma... Lo queremos.

\section{Homenaje al profesor Luis Álvarez Miranda, Oscar Espoueys B.*}

Se nos ha ido el profesor Luis Álvarez Miranda, el último de esos cuatro mosqueteros ariqueños, pioneros de nuestra arqueología y fundadores del Museo Regional de Arica y del Museo San Miguel de Azapa, que fueron: Percy Dauelsberg, Sergio Chacón, Guillermo Focacci y Luis Álvarez. Pioneros sí, porque ese grupo de ariqueños realizó en y para nuestra ciudad muchas obras arqueológicas señeras en nuestra zona, en el Norte Grande, y por qué no también para todo Chile, dado que rescataron la labor del padre de la arqueología de cinco países sudamericanos (Argentina, Bolivia, Perú, Chile y Ecuador), el lingüista y arqueólogo alemán Max Uhle, quien en ese orden consolidó en cada uno de ellos la investigación arqueológica y antropológica científica, investigaciones hoy superadas, pero que fueron innegables hitos para nuestra ciencia entre 1880 y 1960; muy particularmente en nuestra zona, donde descubrió las dos culturas autóctonas, la cultura Chinchorro y sus momias embarradas, y la cultura que hoy lleva el nombre de Arica, con sus maravillosos tejidos, cerámica y cestería, ambas logradas por la misma tradición humana costera y de valles bajos del norte de Chile y extremo sur peruano, zona a la que los Incas denominaran Colesuyo.

Volviendo a Luis Álvarez y sus amigos, ellos además fundaron en 1958 el ya mencionado Museo Regional de Arica, financiando todos sus gastos, y por años lo mantuvieron funcionando y atendiendo gratuitamente a quienes se interesaban en nuestro pasado precolombino. Además, publicaron siete Boletines (1959 a 1961) con informes de sus investigaciones y hallazgos, que afortunadamente fueron reeditados en 1995 por el Departamento de Historia y Geografía de la Universidad de Tarapacá.

Con el apoyo de la Universidad de Chile, sede Arica, y de la Junta de Adelanto, realizaron en nuestra ciudad en 1960 el primer Congreso Arqueológico Internacional celebrado en Chile, reuniendo aquí a los más connotados investigadores de Perú, Bolivia y Argentina de esa época, dando así a conocer nuestra arqueología y nuestra ciudad. Su labor fue fundamental para que en 1968 la Universidad del Norte fundara el Museo Arqueológico de San Miguel de Azapa, del que quedaron a cargo. En esa institución, pese a los cambios de fusiones, de departamentos o de instituciones, que produjeron los avatares de tiempos difíciles, siguieron trabajando, hasta que, como ahora Lucho, nos fueron dejando para siempre.

Los conocí recién llegado a Arica en 1963, cuando, como profano interesado en el pasado de la zona, fui a visitar el Museo Regional.

Reconocieron mi interés por sus trabajos y me fueron invitando a acompañarlos en sus exploraciones e investigaciones, y al lado de ellos, y gracias a sus enseñanzas, fui descubriendo y valorizando su gran labor, y haciéndome ariqueño de corazón, y quedándome de a poco cada vez más ligado al pasado prehispánico de nuestra zona y, por tanto, a ellos.

Su invaluable aporte a la arqueología, y sobre todo al conocimiento del pasado prehistórico de nuestra ciudad, es una deuda que todos los ariqueños tenemos con ellos, aunque para la mayoría sin saberlo realmente. Bueno sería que, habiendo tantas calles en Arica cuyos nombres no evocan nada a la gente, la Municipalidad, haciendo un alto en los avatares electorales que se avecinan, denominara con el nombre de cada uno de dichos investigadores, Uhle incluido, a alguna de ellas y le diera a una plaza un nombre,

* Sociedad Chilena de Arqueología. oespoueys@yahoo.es 
algo así como Arica Arqueológica, donde con actos culturales se los pudiera recordar permanentemente. Tampoco sería mala idea que se creara el Día de la Arqueología y Antropología, para rememorar los pueblos precolombinos y a la etnia aymara, que, aunque no costera, lleva al menos más de 650 años viviendo en Arica, idea que Luis Álvarez habría aprobado.

En lo particular del grupo, fiel a su vocación de profesor, fue Lucho quien, en las salidas a terreno que compartí con ellos, no perdía ocasión de comunicarme sus experiencias de campo, y lo que más llamó mi atención siempre era su capacidad, a la vez, de visualizar el terreno y mantener la concentración en su tema. Por ejemplo, mientras caminábamos, hablaba concentrado en comunicar sus conocimiento, del tema del día, las características geográficas del sitio que recorríamos, o lo que fuera, y de golpe se agachaba sin interrumpir su exposición, recogía una lasca de los cientos que pisábamos al caminar, pero no cualquiera que hubiera llamado su atención, la observaba, y la dejaba o la guardaba en su bolsillo, sin interrumpir su explicación hasta terminarla.

Recién entonces sacaba del bolsillo lo recogido y comenzaba una nueva clase sobre tecnología de talla lítica, un nuevo tema, mostrando una gran capacidad única de no perder la ilación de lo que estaba exponiendo. Y demostrando de paso su poder de observación del entorno, pese a estar hablando sobre otro tema.

Gracias a él, en dos días estuve al tanto de todo lo investigado hasta entonces en Caleta Camarones. Pero a la hora en que alguien avisaba -están picando- Lucho partía automáticamente a buscar la lienza y corría a la playa a asegurar las corvinillas del almuerzo; y en ese caso, sí, la exposición se interrumpía sin previo aviso. Pero si a las cinco o seis de la tarde aún no se había conseguido ni un miserable jurel, ni nada mejor, era hora de echar a la olla apretadores para pasar la noche, previo un buen trago de pisco. Pongo a Hans Niemeyer y a mis hijas de testigos, ya que los otros, desgraciadamente, ya no están con nosotros.

Adiós, profesor Luis Álvarez Miranda.

"Chau" Lucho, muchas gracias por tus invalorables enseñanzas; ojalá sea cierto que pronto podamos encontrarnos con los otros mosqueteros y con Virgilio en la Playa de Camarones para comer los tallarines de Hansito, discutir el resultado del trabajo del día y con qué bibliografía compararlo.

\section{In Memoriam, Luis Álvarez Miranda (1 $1^{\circ}$ junio de 1926-25 de febrero de 2004), Mario Orellana Rodríguez*}

Ha muerto en la ciudad de Arica, el 25 de febrero del año 2004, el distinguido arqueólogo, profesor Luis Álvarez Miranda.

Sus primeros artículos arqueológicos fueron publicados en el Boletín del Museo Regional de Arica los años 1959 y 1960. Ellos probaron, desde el primer momento, su interés por el estudio de las culturas "precerámicas" del extremo norte de Chile. Luego cuando se publicaron en septiembre de 1961 las Actas del "Encuentro Arqueológico Internacional", el primero de este carácter realizado en nuestro país, conocimos su estudio titulado "Manifestaciones precerámicas en la arqueología de Arica", en donde expone los hallazgos de tumbas y, de acuerdo a sus contextos, se esforzó en construir una "cronología relativa" de menor a mayor antigüedad: momias con turbantes, momias cubiertas de arcilla, momias cubiertas de pieles de pelícanos y con anzuelo de concha.

Luis Álvarez formó parte de la primera comunidad científica (arqueológica y antropológica) que se organizó a fines de la década de 1950 en la ciudad de Arica. Las clásicas figuras de F. Max Uhle y de Junius Bird inspiraron, indudablemente, a los jóvenes arqueólogos.

Dirigidos por Percy Dauelsberg, Guillermo Focacci, Luis Chacón y Luis Álvarez constituyeron un equipo científicamente sólido, generoso en la información científica y deseoso de comunicarse con los

* Universidad de Chile. 
arqueólogos de Perú, Bolivia y Argentina, y con los estudiosos que trabajaban en la Universidad de Chile, en la Universidad de Concepción y en los museos del país.

En enero de 1963, en San Pedro de Atacama, cuando se realizó el Congreso Internacional de Arqueología, bajo los auspicios del Museo Arqueológico, cuyo director era el padre Gustavo Le Paige (s.j.), y de la Universidad de Chile, llegó la delegación de Arica encabezada por Percy Dauelsberg y Luis Álvarez. Allí se inició una comunicación personal y permanente entre los colegas de Arica y nosotros. Esta relación científica y de amistad ha terminado con la muerte del último miembro de esta comunidad arqueológica. Sin embargo, sus artículos y libros seguirán siendo analizados por nosotros y por tantos otros estudiosos.

Diferentes congresos de arqueología nos dieron a conocer sus aportes en esta materia. Por ejemplo, en 1969, en La Serena, las actas del congreso contienen su ponencia "Arqueología del Departamento de Arica - Secuencia cultural del período agroalfarero", en donde concluye que "el período preagroalfarero no termina bruscamente con el aparecimiento o introducción de la cerámica y la agricultura en el Departamento de Arica, sino que experimenta una lenta adaptación a una economía sustentada básicamente en el cultivo, en la cría de ganado, en la perfección de los tejidos, en la metalurgia, como en otros aspectos, confundiéndose las fases más tardías, que serían Faldas del Morro, El Laucho y Alto Ramírez con las fases más tempranas del agroalfarero".

Las anteriores consideraciones permiten postular para la zona de Arica un período "de cerámica formativa". Esta hipótesis de Álvarez era una de las que trabajaban los escasos arqueólogos chilenos que investigaban en el norte de Chile.

Ya en 1967, en el Congreso de Concepción, había señalado que los enterramientos precerámicos de "momias de preparación complicada" debían ser situados tentativamente en el período más temprano de los preagroalfareros del extremo norte de Chile.

Así, junto a otros arqueólogos chilenos, Álvarez iba poco a poco ayudando a organizar una cronología relativa con aún muy pocas fechas absolutas.

Aunque con los años, como veremos más adelante, se interesó por los temas "etnográficos", su aprecio por los estudios arqueológicos continuó. En la Revista "Diálogo Andino" N 11-12 (1992-1993), publicó un artículo sobre la "Metalurgia Prehispana Inca en el Sector Costero Marginal del Imperio", como también en el $N^{\circ} 14-15$, de la misma revista (impresa en 1996), escribió "Tras las huellas de Max Uhle: homenaje a Percy Dauelsberg Hahmann", en donde con mucho cariño relaciona la obra de Max Uhle con las investigaciones arqueológicas de Dauelsberg.

Entre sus clases y los cargos académico-administrativos (director de departamento, decano de facultad) continuó publicando, dominando poco a poco otras áreas antropológicas, tales como los temas etnográficos y mitológicos.

Desde la década de 1980 hasta su muerte publicó en la Revista "Diálogo Andino", donde siempre formó parte de su comité editor. Recordemos que esta revista apareció por primera vez en 1982, siendo Álvarez, entre otros, también su director.

Ejemplos de estos nuevos intereses antropológicos fueron sus contribuciones de 1987 ( $\mathrm{N}^{\circ}$ 6), de 1991 $\left(\mathrm{N}^{\circ} 10\right)$ y de 1997 ( $\left.\mathrm{N}^{\circ} 16\right)$, en donde el estudio de la aculturación andino-hispana en el poblado de Socoroma, la etnopercepción andina en los valles "dulces y salados" de la vertiente occidental andina y los temas relacionados con los mitos del mundo aldeano actual le interesaron profundamente. Unido a su vivencia etnográfica y obviamente a sus conocimientos arqueológicos, en Álvarez se descubre también un profundo amor por el estudio espacial. El mismo escribe en abril de 1998, en la presentación que hace de los artículos del $\mathrm{N}^{\circ} 16$, que "el mundo andino, caracterizado por una profusión de escenarios geográficos que se originaron en una diversidad latitudinal y de pisos altitudinales, también lo es rico en cuanto a relatos y tradiciones orales de su población", y señala a continuación que su aporte se refiere al tema "Sireno: dios de la música, recopilación de campo efectuada en el espacio de los Andes de la región de Arica".

Cuando en 1995 coordinó la reedición de los antiguos Boletines del Museo Regional de Arica, publicados entre 1959 y 1961 (siete números), nuestro colega y amigo recordó que "los trabajos incluidos en ellos permitieron en un tiempo y en un espacio conocer parte de un pasado que se logró sólo con el interés de saber más de nuestra prehistoria regional". 
Y estas últimas frases expresaron muy bien la razón del trabajo científico del arqueólogo y antropólogo Luis Álvarez. Con seriedad, sin elaborar conclusiones definitivas, ni menos teorías, apreciando con meticulosidad los datos del pasado, describiendo los restos arqueológicos, las costumbres y las creencias del presente, fue un ejemplo de profesor e investigador. Hombre de "trabajos de campo", amó profundamente no sólo la geografía de sus quebradas, sierras y altos andinos, sino también el mar. No sin razón se le llamaba con cariño "el Chango Álvarez".

Desde la Universidad de Chile, en el Departamento de Antropología, lo recordamos con cariño y con respeto. Esperamos que muchos otros, que no lo conocieron descubran su valor de hombre serio, honesto y estudioso. Sin duda que los estudios arqueológicos y antropológicos del norte de Chile han perdido a uno de sus más distinguidos investigadores.

\section{A Luis Álvarez Miranda, recuerdo para el último de los chinchorros del siglo XX, Luis Briones Morales*}

Así tituló el diario local la noticia del fallecimiento de nuestro colega y amigo Luis Álvarez Miranda, al que recuerdo sobremanera, quizás porque humanamente se acercaba con mayor naturalidad a mi entorno también natural. Nuestra conexión era transparente, afectiva, sincera, casi como si nos hubiésemos conocido desde siempre. Recuerdo aquel momento cuando jóvenes, por los años 54, nos encontrábamos excavando un cementerio inca, junto a Lautaro Núñez, en el oasis de Pica. A eso de las 4 de la tarde en pleno verano, llegó una camioneta blanca con tres menos jóvenes que nosotros preguntando por Lautaro. Eran los amigos de Arica, que para deleite traían, entre sus artificios de terreno, unas cervezas en tarro que yo veía por primera vez... y semicongeladas. Eran las ventajas del puerto libre de ese entonces. Larga fue la conversación conociendo a Percy, Sergio, Luis y el inconfundible Fujito. Esos momentos, breves en el tiempo, están grabados como si hubiese ocurrido ayer y recordando, además, que acababa de cumplir mis primeros quince años de edad. Al cumplir los terceros quince años siguientes, la relación con Luis y los demás fue muy diferente y juntos comenzamos a recorrer otro sendero, esta vez en la Universidad de Chile, Sede Arica, junto a Erie Vásquez, Fujito, a quien Lucho cobijó junto a su familia hasta su muerte. Nuestras reuniones eran en la "vicaría", como le llamábamos al rincón que la Universidad les entregó para usar como "laboratorio de arqueología" y se ubicaba entre artesanos y artistas del Departamento de Artes de esa época. Así, entre ceramistas, canteros, dibujantes, escultores, metaleros, historiadores y teóricos del arte, se iniciaba otra aventura por conocer el legado de nuestros antepasados, esta vez con el complemento y sustento que aporta el mundo del arte. Luis Álvarez lo entendió así, siendo motivo de muchas conversaciones y decisiones que se materializaron en los procesos de valoración, restauración y difusión de los geoglifos de Lluta, Azapa y el Tambo de Copaquilla primero y los geoglifos de Chiza, Unita, Ex Aura y Cerros Pintados después. En esos trotes nos sorprendió la creación de nuestra actual Universidad de Tarapacá. Cuántas jornadas de trabajo en terreno, junto a estudiantes de Arte e Historia y Geografía, conocieron el entusiasmo y la sapiencia del maestro encarnado en el típico hombre del desierto, en el cazador y recolector costero, transportado en el tiempo moderno. La picardía y aguda ironía que muchas veces intercalaba en sus observaciones y conversaciones imprimían más de algún escozor o rubor al que no lo conocía. Era en toda su dimensión, el patriarca, el cacique costero que desde su cátedra universitaria impartía sabiduría universal, en torno a los amigos o colegas, compartiendo un filete de pescado frito en alguna playa ariqueña, participando de su experiencia, de su particular visión de todo lo que se movía en su entorno. Era su forma de ser. Mis últimas conversaciones con el "Negro", como terminé llamándole cariñosamente, fueron sobre los pájaros del estuario del río Lluta. Me arrepiento de no haber llevado una grabadora para capturar esas lecciones que daba con la mayor naturalidad y convicción. Aunque lo pensé, sabía que no le iba a gustar o, por lo menos, le iba a incomodar. Era como escuchar a los mismos pájaros hablando a través de él. Era escuchar a Salvador

* Departamento de Arqueología y Museología. Universidad de Tarapacá, Arica, Chile. lbriones@uta.cl 
Gaviota contando lo que sucedía con todas las especies que proliferan la laguna y la desembocadura del río. Si cambiábamos de escenario y nos trasladábamos al ámbito de los roqueríos, los caletones e islotes de más al sur, Lucho daba lecciones del conocimiento que tenía de ese ambiente, de cómo vivir y sobrevivir hasta en las más extremas situaciones, reconociendo hasta en sus más mínimas características la diversidad de la fauna marina y submarina que se hallaba en el sector. Eran clases magistrales en "vivo y en directo" que no se escuchan en universidad alguna, o no se aprenden con postgrado alguno. Era la vida misma de un "chango" o "chinchorro" moderno, quien hizo lo mismo miles de años atrás. Sus lecciones y recuerdos afloran como dilatando su presencia y motivación para seguir los que seguimos vivos, en donde más temprano que tarde seguiremos por los viejos senderos, algunos, quizás, ya recorridos juntos.

\section{Luis Álvarez Miranda, Mario A. Rivera*}

Con tristeza nos inclinamos ante quien representa el último baluarte de la vieja escuela de la arqueología ariqueña. Lo conocimos en las lides científicas en la década de los sesenta, muy temprano cuando, como estudiantes, idealizábamos con develar misterios sempiternos en la vastedad del desierto. Allí, entre los escasos matorrales en los entornos de Chiu-Chiu, acampando al aire libre, como siempre pregonó, en compañía de aquel inolvidable grupo de precursores, conjuntamente con Percy Dauelsberg, Guillermo Focacci, Sergio Chacón y el inseparable Fujito, en la antesala del Congreso de Arqueología en San Pedro de Atacama.

Hombre de terreno, maestro innato, su inquietud insaciable lo llevó a instruirse en la información arqueológica, nutriéndose de todo aquello que aportara al conocimiento del hombre en el pasado, especialmente ariqueño. De esta inquietud nació su vinculación estrecha con Dauelsberg, Focacci y Chacón y que los llevó a formar el primer centro museológico de esta ciudad, dando las bases para lo que hoy es el Museo Arqueológico San Miguel de Azapa. Su experiencia docente en el Instituto Comercial le valió la entrada posteriormente a la academia universitaria, primero en la Universidad de Chile y posteriormente en la Universidad de Tarapacá. Esforzado pionero, luchó y consiguió educarse a niveles superiores, entregar su formación y experiencia a jóvenes que hoy, convertidos en profesionales, reconocen los valores recogidos por tan noble académico.

Así como escudriñó en el pasado, también quiso asomarse a comprender el momento actual de aquellas sociedades que han heredado la experiencia humana en nuestro norte andino. Investigó innumerables tópicos que se reflejan en su obra escrita, destacando sus trabajos, primero sobre el aporte de Max Uhle, aquel insigne científico alemán que se afincara en esta zona a comienzos del siglo pasado. Luego, y motivado por el influjo de Uhle, sus trabajos sobre la Cultura Chinchorro, tal vez los primeros después de las noticias de Uhle, sobre estos importantes cuerpos momificados de trascendencia mundial. De allí en adelante un sinnúmero de aportes en variados campos, desde la arqueología propiamente tal, a la antropología cultural y a la tradición oral. Recordamos, por ejemplo, sus "Relatos y tradiciones orales andinas. Sireno: dios de la música" (Diálogo Andino 16, 1997), sus trabajos sobre Metalurgia Prehispana, y más recientemente sobre etnohistoria, constituyen una fuente inagotable que contribuyen a la documentación de la historia regional de Arica.

La historia se escribe con obras y Luis Álvarez Miranda, ante todo como educador que fue, nos ha legado una experiencia que, estoy cierto, las generaciones más jóvenes valorarán inmensamente. A nombre de la Universidad Bolivariana que en parte acoge a estos jóvenes que representan la regeneración de la experiencia humana y le dan vitalidad y dinámica a ésta, traspasando y proyectando las imágenes de los que ya no están con nosotros, quiero entregar este reconocimiento postrero a Luis Álvarez, maestro y arqueólogo, que descansa en paz...

* Texto pronunciado con ocasión de la despedida de los restos de Luis Álvarez M. en sus exequias. Arica 26 de febrero de 2004. Universidad Bolivariana, Iquique. mnivera@execpc.com 


\section{Lucho, Erie Vásquez}

¡Vamos, así solamente, Lucho...! Como solíamos llamarlo en Camarones advirtiéndole cuando las olas se venían, con mares bravos, típicos de Semana Santa. O cuando recordábamos a las azapeñas con sus burritos pregonando las sabrosas cañas de azúcar, las mismas que disfrutáramos, manchando incluso nuestras camisas, "made" en casa, con el jugo prodigioso del ya desaparecido fruto tradicional. ¿Recuerdas, Lucho, aquellas camisas...? Simplemente confeccionadas con sacos de harina "Gavilla"... No podíamos aspirar a más. Eran otros tiempos, de volantines y trompos, de verbos que ya no se conjugan ni versos que tampoco se recitan. Lucho no luce ahora el pelo negrísimo ni tampoco su tranco airoso, como aquellos con los que derrotó, en la mítica cancha de la Beneficencia, al crédito iquiqueño del medio fondo, el gran rucio Ernesto Gómez. Muchas cosas hemos perdido, pero a los recuerdos, como al vino, no los mata ni la muerte.

Andábamos por los andurriales azapeños pateando piedras y anchando horizontes cuando Lucho recibía el homenaje de sus pares (UTA) ${ }^{1}$, en un acto en que generalmente se reciben aplausos de compromisos o de buena educación. Esa tarde las palmas se alzaron espontáneas, fraternas, amigas, para aquel que volvía del martirio de anestesias, plasmas y agujas. Su mirada, la imaginamos, perdida, extrañado y vejado en su tradicional sencillez ante tales demostraciones de auténtico aprecio. Lucho es de silencios. De playas con sugerentes atardeceres y orillas plenas de cangrejos y garumitas picoteando los humedales marinos. Es de lenguados sin destinos, ante el tacto maravilloso de los dedos, comunicándose con el pez a través de la línea. Hijo del sacrificio y producto de sus más bellos sueños, acunados en carpas playeras o en sacos de dormir, acurrucado en tantas quebradas nortinas buscando al hombre primordial atacameño. Por su sencillez, aquella tarde de homenaje, no dudamos, habría preferido caminar por Aguas Calientes esperando el bus que lo llevara al alto para encontrarse con los Incas, enseñoreándose por Machu Pichu.

Quizás, estar más al norte, deleitándose con un plato de paiche con chontas, plátanos fritos y yuca, en Iquitos. O volver a pisar las nobles tablas del piso del Archivo de Indias, en Sevilla, donde lo viéramos arrobado paseando su mirada incrédula por la documentación de nuestra América Morena. Nosotros, conociéndolo tanto, lo habríamos preferido, en un lejano 1967, asombrando a los arqueólogos sitos en la Universidad de Concepción, con la ponencia del Complejo Cultural Chinchorro, trabajo de cuatro investigadores ariqueños, creadores del mítico Museo Regional de la calle Sotomayor. Lucho es de otros tiempos, de trompos y volantines, de verbos que ya no se conjugan y de versos que tampoco se recitan.... ¡Vamos, Lucho, los sargos están picando de nuevo en las Yaradas...!

Finalmente, ante la desolación por el mutismo en que cayó este procesador, la nota perdió vigencia y cuando finalmente lo rescaté, decidí no publicarlo en el matutino ariqueño. Premoniciones e influencias que no me atrevo a catalogar, lo cierto es que nuestro amigo partió silenciosamente y esa noche agregamos el epitafio que tanto nos ha dolido.

Ahora, en algún lugar de la dimensión que aún no conocemos, nuestro amigo se inclinará, recogerá una punta de flecha o un fragmento de ceramio, los soplará, y después se endilgará toda una docta charla sobre el hombre primordial de la comarca nortina. Ve, sigue tu camino, Lucho, que nosotros, en tanto, cuidaremos tus recuerdos para que no te olvidemos. Camina, trota, moja tu rostro con la camanchaca, amigo mío; patea los guijarros para que cuando pisemos tu dimensión, caminemos presurosos y podamos ubicarte rápidamente y que, no dudamos, será cerca del mar, descalzo, con el torso desnudo y entrelazando tus manos bajo la espalda curtida de soles, pensando adonde van a morir las gaviotas. Nosotros, amigo, sabemos que allí te encontraremos para reanudar el diálogo que suspendimos momentáneamente mientras te quedabas dormido...

Se refiere al premio a la "Trayectoria al Mérito Académico 2003”, que le entregó la Universidad de Tarapacá, en la celebración de su $22^{\circ}$ aniversario. En ese contexto don Erie Vásquez escribió parte de esta reseña, que terminó el día de su muerte. 


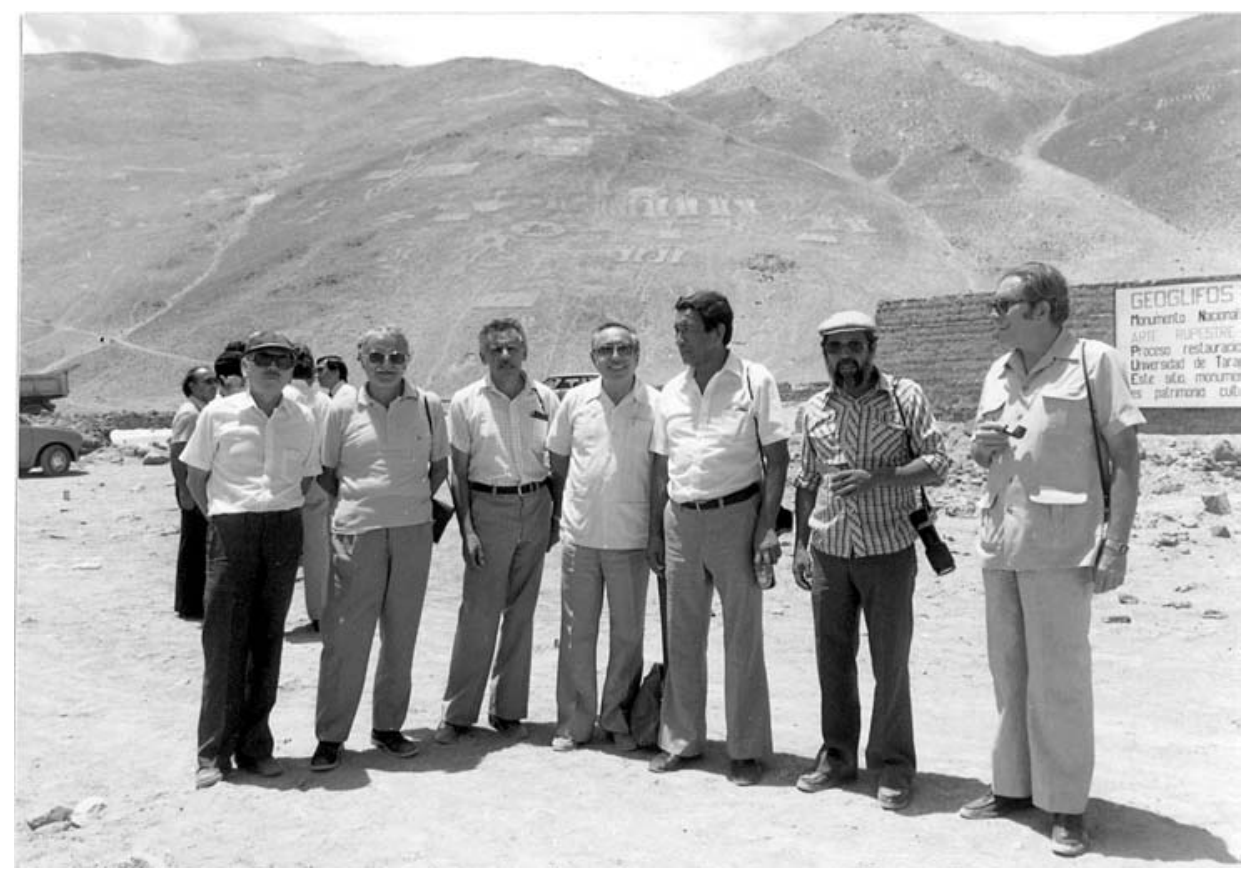

Cerros Pintados, provincia de Iquique, 1981. De izquierda a derecha: Enrique Flores, Sergio Chacón, Guillermo Focacci, Erie Vásquez, Luis Álvarez, Luis Briones y Percy Dauelsberg (Fotografía gentileza de Erie Vásquez).

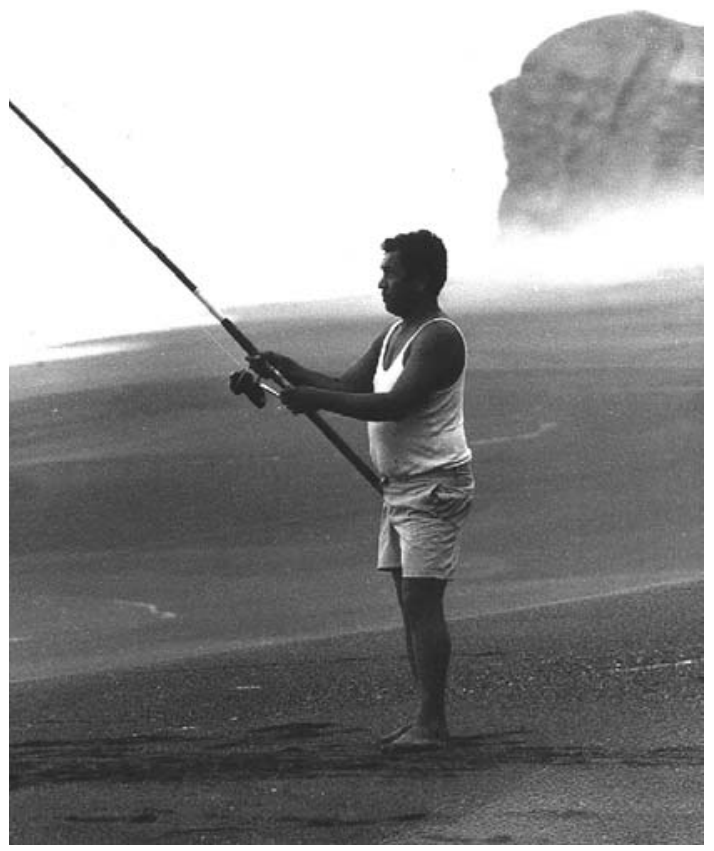

Luis Álvarez en la playa de la desembocadura del río Camarones, año 1980 (Fotografía gentileza familia Álvarez-Inostroza). 


\section{¡Sigamos conversando, hay tanto por hacer!..., Eliana Belmonte Schwarzbaum*}

Construir un año académico sin don Luis no será fácil. Ya lo estoy sintiendo y pensar que recién estamos comenzando abril. Lo que sucede es que mi relación con don Luis siempre fue de creatividad e innovación en tareas formativas y de divulgación. Su calidez como persona, su inquietud por múltiples temas, su visión de futuro, su necesidad de entrega, siempre lo caracterizaron.

Compartimos largas jornadas como académicos en la sede Arica de la Universidad de Chile y continuamos en la Universidad de Tarapacá. Largos años cultivando sueños y estructurando nuevas oportunidades, nuevos escenarios. Su habilidad para captar las inquietudes de los demás lo llevó a entender desde un comienzo mi compulsión por la vida silvestre, y ya en tiempos cuando se iniciaba la reconstrucción del Pukara de Copaquilla me invitó a compartir dicho espacio. Este hecho fue crucial en mi vida profesional y muy pronto inicié mis trabajos de investigación con líquenes, orientándome posteriormente a las plantas vasculares.

Su proximidad y preocupación lo llevaron a abrirme un espacio al interior de su departamento a fines de los ochenta, en momentos difíciles de mi desarrollo profesional, quedando desde entonces ligada al área de las ciencias sociales, tanto en investigación, docencia como extensión.

Como coordinadora de cursos para estudiantes norteamericanos, siempre invité a don Luis a participar; le encargábamos la misión de relatar la historia local. Su sello lo dejaba impreso desde el inicio: “Cómo estructuramos el curso este semestre?”, me decía, y esa sola pregunta daba origen a múltiples conversaciones que generaban, a su vez, otras tantas charlas, siempre insistiendo en temas locales: la agricultura desde sus orígenes, las estrategias de las especies endémicas de flora y fauna, los estilos propios de sobrevivencia, eran todos temas de su dominio. Los resúmenes descriptivos de dichos cursos son parte del legado escrito de don Luis que guardo celosamente, pues mantienen intacta la atmósfera que los generó.

Admiré a don Luis desde un inicio. En aquellos tiempos de la sede Arica de la Universidad de Chile, en una oportunidad nos recibió en la desembocadura de Camarones: nunca olvidaré su estampa erguida, su silueta de moai, delineada contra la puesta de sol, descalzo.

Cuando faltan apenas quince días para el inicio de un nuevo curso para estudiantes extranjeros, echo de menos nuestras conversaciones.

Don Luis: no puedo dejar de agradecerte la forma cómo nos entregaste información. Particularmente importante para mis trabajos fue tu aporte acerca de los "valles dulces y valles salados". No será fácil acostumbrarse a tu ausencia.

\section{A don Luis Álvarez, el gigante de las visiones, Patricia Arévalo Fernández**}

Caminaba siempre solo, en medio de los roqueríos o en medio de la pampa... su tremenda estampa, su color moreno y su voz potente, con las manos tomadas atrás, mirando una vez al suelo y la siguiente al paisaje; lo seguíamos a una distancia moderada -curiosamente a su paso siempre iban quedando tesoros-; los que iban más cerca de él gritaban sus hallazgos: "mire, profesor, encontré una punta de flecha", "y yo unos trozos de cacharros", "y yo unos pedazos de tejidos"... Entonces él con su enorme sonrisa -cómplice de sus recuerdos juveniles- nos corregía: "material lítico"... "fragmentos de cerámica"... "textiles".

Hijo de su tiempo, siempre fue renuente a la participación de las mujeres en las salidas a terreno, aquellas que organizaban el Departamento de Ciencias Sociales y el de Artes para la restauración de geoglifos, decía que eran tarea de hombres. Cuando finalmente accedió a llevarnos, entendimos que eran

\footnotetext{
* Departamento de Arqueología y Museología, Laboratorio de Etnobotánica, Universidad de Tarapacá, Arica Chile. mbelmont@uta.cl

** patsu@netexplora.com
} 
sus escapadas -tan necesarias para él-; igual que los sabios antiguos se hacía rodear por una sociedad secreta [nuestros compañeros]. Allí se hablaba de cosas de hombres, de historia, de geografía, del Arica antiguo y construía imágenes en voz alta.

Todos queríamos ser foco de sus bromas o bautizos; si aparecía el mote o la mención -casi honrosaquería decir que el "Profe" nos había visto. A veces paternal, guió nuestros pasos en la casa de Bello, a veces con una delicadeza que exacerbaba nuestros ánimos feministas; en otras ocasiones certero, seguro, casi implacable con algunos de nosotros, sobre todo con aquellos que parecían carentes de un padre.

Siempre nos llamó la atención que "El Negro" llegara a hacernos clases sin libros, sin apuntes; a veces con el libro de clases, de tarde en tarde un libro de geografía económica para revisar cuántas eran las toneladas anuales de arroz en China. Pocos sabían más que don Lucho de la geografía local; sus "dominios" abarcaban desde la costa hasta los valles, su flora y su fauna, la sierra y sus gentes.

Mientras hacía clases, nos llevaba por un viaje increíble de historias unidas a las gentes y al paisaje; don Lucho sabía cómo se llamaba cada rincón, cómo había evolucionado, cómo había sido ocupado por los antiguos; sus clases de geografía regional terminaban siempre con apuntes Antropológicos y Arqueológicos. Fuimos afortunados, tuvimos un guía que nos enseñó a valorar el paisaje y a escuchar las historias que éste cuenta; a buscar esas mismas imágenes que él veía, las que le ayudaban a reconstruir la vida de los Chinchorro o la lucha de los Arica por el agua o el uso diferido de los valles y entonces hablar de valles dulces y salados se volvió trascendental para nuestra historia; imágenes con las que rodeó un tiempo histórico de 10.000 años.

No hemos olvidado las lecciones aprendidas; después de todo, el mensaje de este gigante reaparece cada vez que el viento sopla libre desde el mar hacia la cordillera, cada vez que baja el río o llegan las garumas en el verano.

\section{Testimonio de Viviana Briones Valentin*}

... Poso la frente sobre río Bravo, Me afirmo pétreo sobre el Cabo de Hornos

Hundo mi brazo izquierdo en el Pacífico

$Y$ sumerjo mi diestra en el Atlántico.

Por las costas de oriente y occidente

Doscientas millas entro a cada océano

Sumerjo mano y mano

$Y$ así me aferro a nuestro continente

En un abrazo latinoamericano.

Nicomedes Santa Cruz, 1971, "Ritmos Negros del Perú".

Fui su alumna durante cinco años en la carrera de Historia y Geografía de la Universidad de Tarapacá. Mucho antes había sido el "tío Lucho" -fue un gran amigo de mi padre- antes de sentir que la historia podría convertirse en una compañera de vida. Antes de ser el maestro, crecí viéndolo como un "tótem", provocaba curiosidad y a orillas del mar -sentado en algún lugar entre la Capilla y Playa Brava- recuerdo haberlo visto comer piure recién sacado y contando alguna historia sobre excavaciones, sobre colegas, sobre su familia, en fin.

Llegó el año 1987 y el tío Lucho se convirtió en el "profe". Por generaciones se sabía que sus cátedras eran imperdibles. Faltar a una de sus clases significaban a lo largo del semestre académico horas extras de estudio, horas extras de lectura, esto último no menos importante para un estudiante de Historia.

Nadie puede olvidar sus memorables cátedras de Geografía de Eurasia. Cada cumbre, cada ciudad, lago, río, etc. era recitado por el maestro. Aterrador resultaba salir a un mapa y responder acertadamente

* Universidad de Tarapacá, Centro de Investigaciones del Hombre en el Desierto, Proyecto Fondecyt 1030020. 
a sus interrogaciones. Era una mezcla de desafío personal-intelectual para probar al límite nuestro sistema nervioso. Era riguroso e implacable ante la falta de disciplina, pero a la vez el maestro sabía cómo estimularnos a ser "seres críticos", buenos observadores, tolerantes a nuestras frustraciones, constantes en las tareas estudiantiles, librepensadores y, por sobre todo, evitar la soberbia intelectual.

Todos sus alumnos sabíamos de su trayectoria profesional. Pionero en la arqueología local, conocedor de cada espacio ariqueño, la historia de la ciudad se paseaba por su vida, era excelente caminante y eficiente hombre de terreno. Fue así que los trabajos de campo se convirtieron en anhelados momentos. Junto con otros profesores, lo seguimos al altiplano, quebradas y sitios arqueológicos en la costa. En estas experiencias no sólo aprenderíamos a ser buenos conocedores de nuestro entorno, sino también ser responsables en el cuidado de la memoria local, del patrimonio cultural y arqueológico y del valor de hacer una historia "desde abajo", en un esfuerzo por rescatar a aquellos que la historia oficial no contemplaba: a los "sin voz".

Algunos de nosotros privilegiamos la investigación ante la pedagogía. Tenía sus reparos, pero siempre supo decir palabras alentadoras. También algunos quisimos seguir mirando el pasado regional y en cada nuevo avance siempre fue importante la opinión de don Lucho.

Volveremos en alguna oportunidad a Socoroma, Belén, Tojo-Tojone, Camarones, Molinos, Livilcar, Caleta Vitor, Putre, etc. Allí siempre estará usted, con su buen humor, incansable, profesor, colega y también amigo de casi tres generaciones de profesores de Historia y Geografía que lo recordarán con permanente respeto y profundo cariño.

\section{Saludo a don Luis Álvarez Miranda, Calogero M. Santoro*}

Don Luis Álvarez Miranda, profesor de la Universidad de Tarapacá, geógrafo, prehistoriador, fundador de la Sociedad Chilena de Arqueología, del Museo Regional de Arica, de la Revista Dialogo Andino, gran hombre de la costa del desierto y, posiblemente, uno de los últimos representantes de los grupos de pescadores que arribaron a estas tierras hace miles de años, dejó de respirar en la tarde del 25 de febrero de 2004, en su casa de Arica, junto a su numerosa familia. Esta noticia ha impactado a la comunidad científicoarqueológica local, nacional e internacional; a la sociedad de Arica y a la comunidad universitaria en particular, que lo despidieron en un multitudinario cortejo fúnebre bajo el sol del mediodía.

En este contexto, quisiera resaltar algunos aspectos de su vida, en el campo profesional. De palabra franca, directa y sin ambigüedades, a don Luis Álvarez se le reconoce el gran mérito de haber iniciado una nueva etapa en la historia de la arqueología chilena, como así también andina, en la medida que, junto a sus compañeros, Guillermo Focacci, Percy Dauelsberg y Sergio Chacón, y la colaboración desinteresada de otros amigos como Fujito, Luis Valdivia, Erie Vásquez, formaron un grupo dedicado al estudio de la prehistoria regional y con mucha pasión enfrentaron, en la década de los cincuenta, la compleja y multifacética materialidad cultural de la arqueología de la zona de Arica y áreas vecinas. En esa época la arqueología de Arica se conocía fuera del país por los estudios fundacionales de Max Uhle, Junnius Bird y Carlos Munizaga. Este grupo de pioneros locales, sin embargo, no desarrolló un simple club de exploradores; por el contrario, con sus actividades de investigación crearon instituciones fundamentales para la cultura y la educación, como el Museo Regional de Arica. Organizaron la primera reunión de arqueología nacional e internacional, que se transformó en el Primer Congreso Nacional de Arqueología Chilena, y sirvió de base también para la fundación de la Sociedad Chilena de Arqueología. Más tarde y en esta misma línea de acción fundó la Revista Diálogo Andino, un importante medio de difusión científica de la Universidad de Tarapacá, de la que fue su director hasta hace pocos meses. Al profesor Luis Álvarez se le reconoce, también, una fructífera e influyente actividad docente, primero

* Centro de Investigaciones del Hombre en el Desierto, Departamento de Arqueología y Museología, Universidad de Tarapacá, Arica, Chile. 
como profesor del Instituto Comercial de Arica y luego, a través de la formación de profesores en la carrera de pedagogía en historia y geografía, la que también ayudó a organizar en la ex sede de la Universidad de Chile en Arica.

Toda su obra como educador, como científico y como ciudadano en este rincón de la costa de Sudamérica fue motivada por un espíritu de búsqueda y creación intelectual que mantuvo envidiablemente viva hasta el final. Una necesidad vital de estudiar en los términos de Ortega y Gasset. Esta necesidad lo llevó a ser un buen conocedor de la geografía regional, que describió y conceptualizó con relación a la historia de los pueblos prehispánicos que habitaron los valles, sierra y altiplano del desierto de la región.

Mención especial merece su fascinación por la costa, como si hubiera tenido el mandato de miles de generaciones de pescadores recolectores del Pacífico, conocidos ahora como changos, de relatar con base en los restos conservados en las arenas del desierto su milenaria historia. Don Luis Álvarez, este es un mensaje de respeto y admiración por su perseverancia y dedicación al cultivo de la ciencia y la educación. Los changos, la ciudad, el país, la humanidad que lo han despedido han ganado un símbolo para esta tierra. 
9 